analogous results from research into schizophrenia ${ }^{24}$ ) but all participants who completed the experimental treatment reported treatment gains. The effects of the experimental treatment were large and may have been reduced because some patients in the control group will have probably tried to recognise prodromal symptoms of relapse on their own. ${ }^{10}$

The experimental treatment does not require a skilled therapist, but attention to detail is essential to identify accurately the nature and timing of prodromal symptoms of manic relapse. Cost effectiveness studies of the identification of manic prodromes followed by early treatment are required before the intervention is systematically introduced into the NHS.

We thank Brian Faragher for statistical advice and our colleagues in South Manchester, Guild (Preston), Trafford, and Stockport NHS Trusts who referred patients.

Contributors: NT and RM designed the protocol, initiated and coordinated the study, successfully applied for funding, interpreted the data, and wrote the paper. NT and RM are guarantors of the study. NT and AP designed the experimental treatment and NT supervised AP in delivering the experimental treatment. AP, EMcC, and RM analysed the data. AP, KL, and $\mathrm{EMcC}$ recruited patients into the trial and executed the trial.

Funding: This study was funded by a project grant awarded

by the North West Regional Health Authority.

Competing interests: None declared.

1 American Psychiatric Association. Diagnostic and statistical manual of mental disorders, third edition revised. Washington, DC: APA, 1987.

2 Coryell W, Keller M, Endicott J, Andreasen N, Clayton P, Hirschfeld R. Bipolar II illness: course and outcome over a five year period. Psychol Med 1989;19:129-41

3 Harrow M, Goldberg JF, Grossman LS, Meltzer HY. Outcome in manic disorders. A naturalistic follow-up study. Arch Gen Psychiatry 1990;47:66571.

4 Tohen M, Waternaux GM, Tsuang MT. Outcome in mania: a 4 year prospective follow-up of 75 patients utilising survival analysis. Arch Gen Psychiatry 1990:47:1106-11.

5 Keller MB, Lavori PW, Coryell W, Endicott J, Mueller TI. Bipolar I: a five year prospective follow up. J Nerv Ment Dis 1993;181:238-45.
6 Gitlin MJ, Swendsen J, Heller TL, Hammen C. Relapse and impairment in bipolar disorder. Am J Psychiatry 1995; 152:1635-40.

7 Keck PE, McElroy SL, Strakowski SM, West SA, Sax KW, Hawkins JM, et al. 12 month outcome of patients with bipolar disorder following hospitalisation for a manic or mixed episode. Am J Psychiatry 1998;155: 646-52.

8 Molnar G, Feeney M, Fava G. The duration and symptoms of bipolar prodromes. Am J Psychiatry 1988;145:1575-8.

9 Smith J, Tarrier N. Prodromal symptoms in manic depressive psychosis Soc Psychiatry Psychiatric Epidemiol 1992;27:245-8.

10 Lam D, Wong G. Prodromes, coping strategies, insight and social functioning in bipolar affective disorders. Psychol Med 1997;27:1091-100.

11 Altman ES, Rea MM, Mintz J, Miklowik DJ, Goldstein MJ, Hwang S. Prodromal symptoms and signs of bipolar relapse: a report based on prospectively collected data. Psychiatr Res 1992;41:1-8.

12 Keller MB, Lavori PW, Kane JM, Gelenberg AJ, Rosenbaum JF, Walzer EA, et al. Subsyndromal symptoms in bipolar disorder: a comparison of standard and low serum levels of lithium. Arch Gen Psychiatr 1982;49:371-6.

13 Spitzer RL, Williams JBW, Gibbon M, First MB. Structured clinical interview for DSM-III-R, patient edition. Washington, DC: APA, 1990.

14 Pocock ST. Clinical trials: a practical guide. Chichester: Wiley, 1983

15 Kessing LV. Recurrence in affective disorder. II. Effect of age and gender. Br J Psychiatry 1998;172:29-34.

16 Maj M, Pirozzi R, Magliano L, Bartoli L. Long-term outcome of lithium prophylaxis in bipolar disorder: a 5-year prospective study of 402 patients at a lithium clinic. Am J Psychiatry 1998;155:30-6.

17 Miklowitz D, Goldstein M, Nuechterlein K, Snyder M, Mintz J. Family factors and the course of bipolar affective disorders. Arch Gen Psychiatry 1988;45:225-30.

18 Perry A, Tarrier N, Morriss R. Identification of prodromal signs and symptoms and early intervention in manic depressive psychosis patients: a case example. Behav Cognit Psychother 1995;23:399-409.

19 Young MA, Grabler P. Rapidity of symptom onset in depression. Psychiat Res 1985;16:309-15.

20 Hurry J, Sturt E, Bebbington P, Tennant C. Socio-demographic associations with social disablement in a community sample. Soc Psychiatry 1983;18:113-21.

21 World Health Organisation. Anatomical therapeutic chemical (ATC) classification index including defined daily doses (DDDs) per plan substances. Oslo: WHO Collaborating Centre for Drug Statistics and Methodology, 1994.

22 Hlastala SA, Frank E, Mallinger AG, Thase ME, Ritenour AM, Kupfer DJ Bipolar depression: an underestimated treatment challenge. Depression Anxiety 1997;5:73-83.

23 Gater RA, Dean C, Morris J. The contribution of childbearing to the sex difference in first admission rates for affective psychosis. Psychol Med $1989 \cdot 19 \cdot 719-24$

24 Tarrier N, Yusupoff L, Kinney C, McCarthy E, Gledhill A, Haddock G, et al. Randomised controlled trial of intensive cognitive behaviour therapy for patients with chronic schizophrenia. BMJ 1998;317:303-7.

(Accepted 28 October 1998)

\title{
Association between maternal anxiety in pregnancy and increased uterine artery resistance index: cohort based study
}

Jerónima M A Teixeira, Nicholas M Fisk, Vivette Glover

\begin{abstract}
Objective To investigate whether maternal anxiety in the third trimester is associated with an increased uterine artery resistance index.

Design Cohort based study.

Subjects 100 pregnant women, with a mean gestation of 32 weeks.

Outcome measures Self rating Spielberger questionnaire for state anxiety and trait anxiety, and uterine blood flow waveform patterns as assessed by colour Doppler ultrasound.

Results A significant association was found between uterine artery resistance index and scores for both Spielberger state anxiety and trait anxiety $\left(r_{\mathrm{s}}=0.31\right.$, $\mathrm{P}<0.002$ and $0.28 \mathrm{P}<0.005$ respectively). Women with state anxiety scores $>40(n=15)$ had a higher mean uterine resistance index than those with scores
\end{abstract}

$\leqslant 40$ (mean difference with mean resistance index $24 \%, 95 \%$ confidence interval $12 \%$ to $38 \%$; $\mathrm{P}<0.0001)$. Similarly, women with trait anxiety scores $>40(n=32)$ had a higher mean resistance index than those with scores $\leqslant 40$, although to a lesser extent. The presence of notches in the waveform pattern produced by uterine artery blood flow was found in 4/15 (27\%) women with high state anxiety scores compared with $4 / 85(5 \%)$ with low anxiety scores $(\mathrm{P}<0.02)$

Conclusions This study shows an association between maternal anxiety in pregnancy and increased uterine artery resistance index. It suggests a mechanism by which the psychological state of the mother may affect fetal development, and may explain epidemiological associations between maternal anxiety and low birth weight. The influence of maternal anxiety may be one mechanism by which
Centre for Fetal Care, Division of Paediatrics,

Obstetrics and

Gynaecology,

Queen Charlotte's and Chelsea

Hospital, London W6 $0 \mathrm{XG}$

Jerónima M A

Teixeira,

research fellow

Nicholas M Fisk, professor of obsetrics and gynaecology

Vivette Glover,

reader in perinatal psychobiology

Correspondence to: Dr Glover vglover@rpms.ac.uk

BMJ 1999;318:153-7 
the intrauterine environment contributes to later disease in offspring.

\section{Introduction}

The belief that a mother's psychological state can influence her unborn baby exists in most societies. ${ }^{1}$ Some studies have shown that babies of stressed or anxious mothers have a significantly lower average birth weight for gestational age and tend to be born early. ${ }^{2-5}$ In one large case-control study, the magnitude of the effect of stress on birth weight was similar to that found in the offspring of mothers who smoked. ${ }^{6}$ As low birth weight seems to be associated with health problems in later life-for example, hypertension and ischaemic heart disease - this is of concern. ${ }^{7}$ Ultrasound studies have shown that fetal behaviour is affected by maternal anxiety. ${ }^{8}{ }^{9}$ Animal studies have also shown that when the mother is stressed during pregnancy, birth weight is reduced and the behaviour of the progeny is permanently affected. ${ }^{10} 11$

There are several mechanisms by which maternal stress or anxiety might affect the fetus. Increased concentrations of hormones in the mother may be transported directly across the placenta. ${ }^{12}$ Blood flow to the baby may also be impaired through the uterine arteries. Such an effect has been shown in primates, but has not yet been studied in humans. ${ }^{13}$ We tested the hypothesis that anxiety in pregnant women is associated with abnormal blood flow in the uterine arteries. This was assessed by using colour Doppler ultrasound to both measure uterine artery resistance index and to detect the presence of notches in the waveform pattern produced by uterine blood flow (fig 1). A notch indicates particularly high resistance to blood flow. These variables have previously been associated with adverse obstetric outcome, particularly fetal growth restriction and pre-eclampsia..$^{14-16}$

\section{Subjects and methods}

\section{Subjects}

Between April and December 1996, we asked 182 pregnant women at parentcraft classes if they would agree to participate in our study. Overall, 119 women with singleton pregnancies between 28 and 32 weeks of gestation agreed to participate within the next four weeks. Women who refused to participate did so mainly because of a lack of a mutually convenient appointment time; the proportion of these women $(\mathrm{n}=63)$ with pre-eclampsia $(\mathrm{n}=3)$ and small for gestational age babies at birth $(<5$ th centile; $n=3)$ was similar to the final cohort. We obtained informed written consent from each woman. We excluded women on the basis of the following criteria: (a) medical disease, including known pre-eclampsia or antepartum haemorrhage, (b) smoking, (c) previous adverse obstetric outcome, such as preterm delivery and small for gestational age baby, $(d)$ assisted conception, (e) abnormal volume of amniotic fluid or abnormal velocity waveforms from the umbilical artery, $(f)$ known small for gestational age fetus $(<5$ th centile) on a previous scan, and $(g)$ multiple pregnancy. Outcome data were obtained from the hospital obstetric database. Seven women were subsequently excluded from data analysis because of incomplete questionnaires or unclear uterine velocity waveforms. Overall, 100 women met the inclusion criteria.

\section{Questionnaires}

Immediately before Doppler ultrasound, the women completed two questionnaires. The first was a simple questionnaire to ascertain their history of emotional problems, major life events in the past 3 months, and alcohol intake (none consumed more than one unit a day). The second was the Spielberger questionnaire, which comprises two parts measuring both state anxiety and trait anxiety. ${ }^{17}$ For state anxiety, subjects are asked how they feel at the time of being questioned, and for trait anxiety, subjects are asked how they feel generally. Before the study, a cut off point of scores $>40$ was selected for both state anxiety and trait anxiety. $^{18}$

\section{Doppler ultrasound}

We recorded the Doppler flow velocity waveforms using an Acuson XP 10 or Sequoia ultrasound machine (Acuson, CA, USA) with a 3.5 or $5 \mathrm{MHz}$ probe. These were later analysed by the same operator (JT), blind to the questionnaire results. Colour Doppler ultrasound was used to identify the main branch of the uterine artery at its junction with the internal iliac artery, from where we obtained blood flow velocity waveforms. Waveforms were recorded from both uterine arteries, and from the fetal middle cerebral artery and umbilical artery in standard fashion. We derived the resistance index for the uterine arteries (fig 1), and the pulsatility index $(\mathrm{A}-\mathrm{B} /$ mean waveform height (fig 1) for fetal vessels, from five consecutive uniform waveforms. The mother's heart rate at the time of scanning
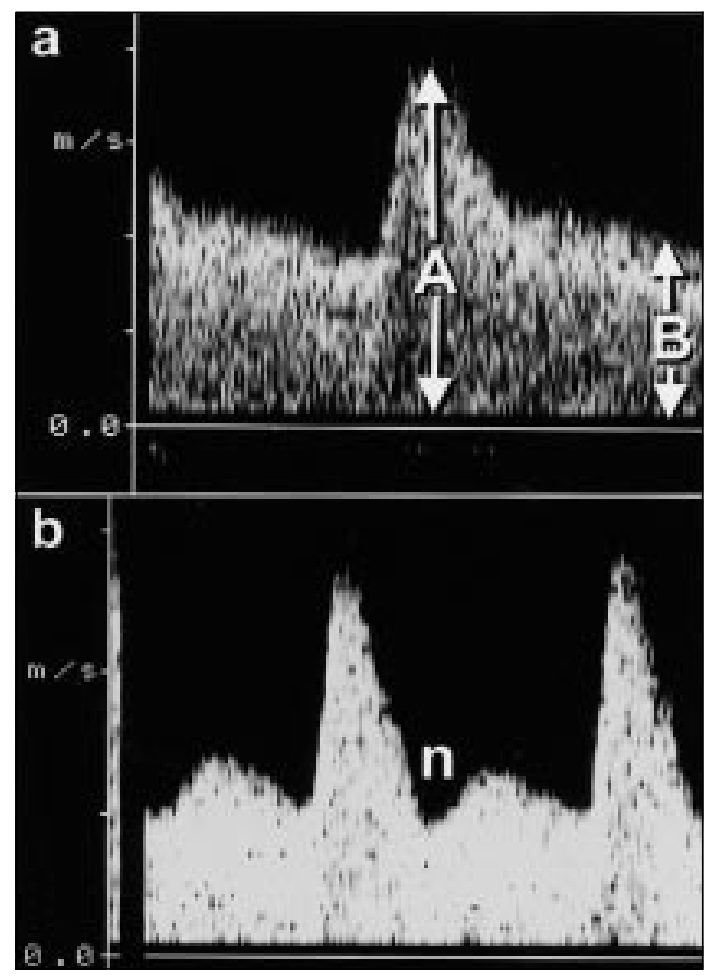

Fig 1 Uterine artery waveforms: (a) normal, (b) abnormal. Resistance index=(A-B)/A. A notch (n) indicates particularly high resistance to blood flow 
was similarly derived. The presence or absence of a notch in each uterine waveform was noted, and subjects were considered positive if the notch was present unilaterally. The coefficient of variation for the repeated measurement of resistance index was $6 \%$. All 100 women had complete Doppler ultrasound studies of the uterine artery with full data for mean resistance index, maximum resistance index, and notching. Only 84 women had full fetal Doppler ultrasound studies; complete fetal Doppler data were obtained from 13/15 women with high state anxiety scores (high anxiety group) and from 71/85 women with low state anxiety scores (low anxiety group).

\section{Statistics}

Mean resistance index was calculated as the mean value from both left and right uterine arteries. Maximum resistance index was the maximum of the mean values obtained from either artery. Continuous variables were tested for normality, and variables that were not distributed normally were transformed appropriately. The following tests were used as appropriate: Student's $t$, Mann Whitney U, Fisher's exact, and Wilcoxon matched pairs tests. All the tests were two tailed.

\section{Results}

In the final cohort of 100 women, the state anxiety score was lower than the trait anxiety score: median (range) $28.5(20-61)$ versus $36(20-67) \quad(\mathrm{P}<0.001)$ Fifteen women scored $>40$ for state anxiety, and 32 women scored $>40$ for trait anxiety.

A significant association was found between maximum resistance index and both state anxiety scores $\left(r_{\mathrm{s}}=0.31, \mathrm{P}<0.002\right)$ and trait anxiety scores $\left(r_{\mathrm{s}}=0.28, \mathrm{P}<0.005\right)$, and between mean resistance index and both state anxiety scores $\left(r_{\mathrm{s}}=0.28, \mathrm{P}<0.005\right)$ and trait anxiety scores $\left(r_{\mathrm{s}}=0.21, \mathrm{P}<0.03\right)$. Figure 2 shows the data for maximum resistance index.

When the groups were dichotomised, using the predetermined cut off point of a score of $>40$, women in the high state anxiety group had significantly worse uterine velocity waveforms than those in the low state anxiety group, whether considered as mean resistance index, maximum resistance index, or notching (table); mean difference in mean resistance index 24\%; 95\% confidence interval $12 \%$ to $38 \% ; \mathrm{P}<0.0001$; and mean difference in maximum resistance index $23 \% ; 10 \%$ to $37 \% ; \mathrm{P}<0.0005$. Using trait anxiety $(>40)$, there were also differences between high and low anxiety groups (mean difference in mean resistance index 13\%; 4\% to $23 \% ; \mathrm{P}<0.005$ ); and mean differences in maximum resistance index (mean increase $16 \% ; 6 \%$ to $26 \%$; $\mathrm{P}<0.001)$. The 15 women who had the highest trait anxiety scores (12 of whom also had high state anxiety scores), had similar mean and maximum resistance indexes to the 15 women who had high state anxiety scores ( 0.56 . and 0.63 respectively). Those women who had low scores for state anxiety but high scores for trait anxiety $(n=20)$ were not significantly different for mean or maximum resistance indexes from those women with low scores for both state anxiety and trait anxiety $(\mathrm{n}=65)$.

We also compared the two state anxiety groups for the proportion of women with a resistance index of
Uterine Doppler ultrasound characteristics in 100 mothers with either low $(\leqslant 40)$ or high (>40) Spielberger state anxiety scores. Values are geometric means $(95 \%$ confidence intervals) unless stated otherwise

\begin{tabular}{lccc} 
& $\begin{array}{c}\text { Low anxiety scores } \\
(\mathbf{n}=\mathbf{8 5})\end{array}$ & $\begin{array}{c}\text { High anxiety scores } \\
(\mathbf{n = 1 5})\end{array}$ & P value \\
\hline Mean resistance index & $0.47(0.45$ to 0.49$)$ & $0.58(0.50$ to 0.67$)$ & $<0.0001$ \\
\hline Maximum resistance index & $0.51(0.49$ to 0.54$)$ & $0.63(0.56$ to 0.71$)$ & $<0.0005$ \\
\hline No (\%) with mean resistance index $\geqslant 0.68$ & $3(4)$ & $4(27)$ & $<0.01$ \\
\hline No $(\%)$ with notching & $4(5)$ & $4(27)$ & $<0.02$
\end{tabular}

0.68 or above - that is, the upper limit of the $95 \%$ reference range for a mean gestation of 32 weeks. ${ }^{19}$ In the most anxious group, 4/15 (27\%) women had a mean resistance index $\geqslant 0.68$ compared with $3 / 85(4 \%)$ women in the less anxious group $(\mathrm{P}<0.01)$ (table). Of the seven women with mean resistance indexes $\geqslant 0.68$, six had high trait anxiety scores.

The group of women with a notch was overlapping but distinct from those with a resistance index $\geqslant 0.68$. The group had a mean (SD) resistance index of 0.6 (0.1). The presence of a notch (unilateral or bilateral) was associated with state anxiety; $4 / 15$ women in the high anxiety group had a notch compared with $4 / 85$ women in the low anxiety group $(\mathrm{P}<0.02)$. All but one of those with a notch had high scores for either state anxiety or trait anxiety. The remaining patient scored 20 (in effect zero) on both scales.

The best multiple regression model to predict mean resistance index comprised state anxiety scores $(\mathrm{P}<0.001)$ and maternal heart rate $(\mathrm{P}<0.02)$, whereas to predict maximum resistance index or notching, the best multiple regression model comprised only state anxiety scores $(\mathrm{P}<0.01)$ for both.
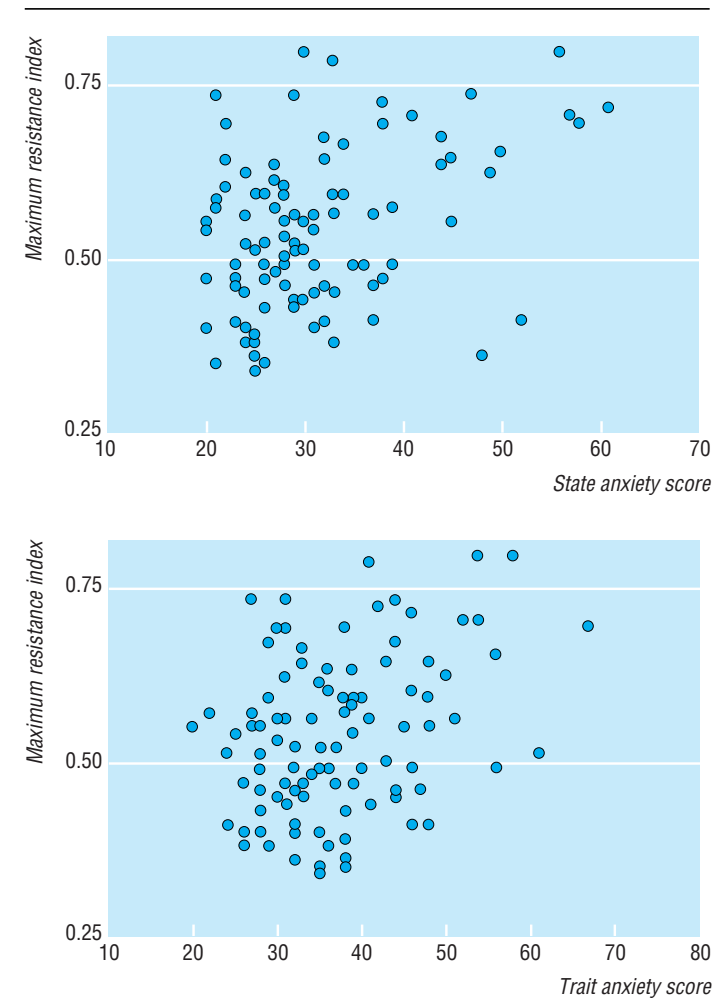

Fig 2 Correlation between maximum resistance index and scores for both state anxiety $\left(r_{\mathrm{s}}=0.31, \mathrm{P}=0.00180\right)$ and trait anxiety $\left(r_{\mathrm{s}}=0.28\right.$, $\mathrm{P}=0.0048)$ in 100 pregnant women 
No significant differences were found in the clinical variables studied between the high and low anxiety groups, whether divided by state anxiety or trait anxiety. For the mother these included age, maternal heart rate, parity, and emotional history or life events during this pregnancy. For the fetus they included birth weight, estimated fetal weight and gestational age at Doppler ultrasound, fetal heart rate, and pulsatility index of the umbilical and middle cerebral artery. All subjects were normotensive $(<120 / 90)$ at the time of Doppler analysis. Four women developed pre-eclampsia before delivery, all in the low anxiety groups; one woman had a notch and high resistance index (mean 0.7), and the other three women had normal uterine waveforms. Six fetuses were small for gestational age at birth. The median mean resistance index value for these was 0.6 (range 0.42 to 0.73 ).

\section{Discussion}

This study shows an association between anxiety and a high resistance index whether analysed as continuous data (fig 2) or dichotomised (table). Women with increased anxiety are more likely to have abnormal variables for uterine artery blood flow than those with less anxiety, whether considered as mean resistance index, maximum resistance index, or notching. This association was more pronounced for state anxiety than for trait anxiety. There were, however, more women in the high trait anxiety group than in the high state anxiety group.

Furthermore those women with abnormal Doppler ultrasonograms were more likely to be anxious. All eight women with a notch had an abnormal score on the Spielberger questionnaire ( 0 scores often signify denial and an underlying psychopatholog $\left.y^{20}\right)$. In addition, $6 / 7$ women with resistance indexes $\geqslant 0.68$-that is, the 95th centile--had high anxiety scores, four had high state anxiety scores, and six had high trait anxiety scores.

Women with high state anxiety scores had slightly, although insignificantly, faster heart rates. However, we used multiple regression to show that the association between mean resistance index and state anxiety score was not a confounding effect of maternal heart rate.

The 100 women we studied seem reasonably representative of a non-selected population. Seven had mean resistance indexes on or above the 95th centile, eight had notches (a similar freqency to that found in a large population study ${ }^{16}$ ), six had babies with birth weights at or below the 5th centile. In the general population about $30 \%$ of women score $>40$ for both state anxiety and trait anxiety. ${ }^{21}$ We observed the same proportion for trait anxiety scores, but not for state anxiety scores. State anxiety scores were lower. It may be that pregnancy in itself was relaxing, at least in the middle of the third trimester in this cohort of women with no obstetric complications.

The Doppler ultrasound waveforms studied here predominantly represent downstream resistance, and not strictly blood flow. However, assuming a relatively stable cardiac output, they are a reasonable index of uterine blood flow. Studies on Doppler ultrasound of uterine arteries to predict impaired trophoblastic inva-
- Women who were anxious during pregnancy had significantly abnormal patterns of blood flow through the uterine arteries

- Of the most anxious group, $27 \%$ had an increased resistance index of clinical concern, compared with $4 \%$ in the less anxious group

- The study did not establish whether the impaired blood flow was predominantly linked with state anxiety or trait anxiety

- The findings may help to explain previous studies that have linked stress or anxiety in pregnancy with small for gestational age babies

sion have attempted to concentrate on the side supplying the placenta. In this study we have chosen to determine the mean of the resistance indexes on both sides of the uterus (mean resistance index), because ascribing placentation entirely to one side is necessarily artificial. As the highest resistance index (maximum resistance index) is the more abnormal, and possibly thus more clinically relevant, we also analysed this. Whether mean or maximum resistance index was used, the results were generally similar. Impaired uterine blood flow is generally considered a chronic phenomenon, predominantly due to failure of invasion of the placenta by the trophoblast in early pregnancy, ${ }^{22}$ and abnormal patterns, either high resistance indexes or notching, are predictive of preeclampsia and intrauterine growth retardation. ${ }^{16}$ This does not, however, exclude later changes in uterine blood flow, such as might be associated with transient changes in maternal hormone concentrations, as shown in animal models. ${ }^{23}$ Indeed, exercise transiently increases uterine resistance indexes in pregnant women at around 34 weeks of gestation, ${ }^{24}$ and treatment interventions can acutely improve blood flow. ${ }^{25} 26$

The hypothalamic-pituitary-adrenal axis may be involved in the altered blood flow pattern described here, ${ }^{27}$ but an obvious candidate for mediator is noradrenaline. High scores for state anxiety are associated with increased plasma noradrenaline concentrations. ${ }^{28}$ Also, infusion of noradrenaline decreases uterine blood flow, both in pregnant sheep and pregnant guinea pigs. ${ }^{23}{ }^{29} \mathrm{In}$ fact, in sheep, reproductive tissues (including the uterus) were more sensitive to the vasoconstrictive effects of noradrenaline than were other body tissues. ${ }^{29}$ It may be that in times of stress the mother has evolved to protect herself at the expense of her fetus. ${ }^{30}$

We do not know whether the associations between anxiety and Doppler ultrasonograms are acute or chronic. Although we found stronger associations for state anxiety than for trait anxiety, the top $15 \%$ of women with either score were largely the same patients, and had similarly abnormal waveforms. Further work is needed to determine whether overall anxiety during pregnancy or even before or at conception might affect uterine artery blood flow, or instead whether the association is only with the current 
emotional state. It is also possible that there is some underlying factor that causes both increased anxiety and diminished trophoblastic invasion. It is unlikely that the women in our study had reason to be concerned about the progress of their pregnancy, as we excluded those with pre-eclampsia or fetal growth retardation known before Doppler ultrasound.

Although there are many contributors to fetal growth and birth weight, reduced blood flow through the uterine arteries could partially explain why women who are anxious during pregnancy tend to have smaller babies. It is also possible that this mechanism is related to some of the findings by Barker, ${ }^{71}$ which have linked low birth weight to a later predisposition to coronary heart disease.

We thank the Henry Smith Charity, the Children Nationwide Medical Research Fund, the John Ellerman Foundation, Caroline Doré for statistical advice, and Diana Adams for patient recruitment.

Contributors: JMAT conducted the Doppler studies, analysed the raw data, and refined drafts of the paper; he will act as guarantor for the paper. NMF refined the study design and drafts of the paper, supervised the Doppler studies, and contributed to statistical analysis. VG originated the study, supervised the psychometric testing, and drafted the paper.

Funding: JMAT was supported by the Calouste Gulbenkian Foundation, Portugal.

Conflict of interest: None

1 Ferreira AJ. Emotional factors in prenatal environment. J Nervous Men Dis 1965;141:108-18.

2 Perkin MR, Bland JM, Peacock JL, Anderson HR. The effect of anxiety and depression during pregnancy on obstetric complications. Br J Obste Gynaecol 1993;100:629-34

3 Wadwa PD, Sandman CA, Porto M, Dunkel-Schetter C, Garite TJ. The association between prenatal stress and infant birth weight and gestational age at birth: a prospective investigation. Am J Obstet Gynecol 1993; 169:858-65.

4 Copper RL, Goldenberg RL, Das A, Elder N, Swain M, Norman G, et al. The preterm prediction study: maternal stress is associated with spontaneous preterm birth at less than 35 weeks gestation. Am J Obstet Gynecol 1996;175:1286-92.

5 Hedegaard M, Henriksen TB, Secher NJ, Hatch MC, Sabroe S. Do stressful life events affect the duration of gestation and risk of preterm delivery? Epidemiology 1996;7:339-45.

6 Lou HC, Hansen D, Nordenfoft M, Pryds O, Jensen F, Nim J, et al. Prenatal stressors of human life affect fetal brain development. Dev Med Child Neurol 1994;36:826-32.

7 Barker DJ. The fetal origins of adult disease. Proc R Soc Lond B Biol Sci 1995;262:37-43.

8 Ianniruberto A, Tajani E. Ultrasonographic study of fetal movements. Semin Perinatol 1981;5:175-81.

9 Groome LJ, Swiber MJ, Bentz LS, Holland SB, Atterbury JL. Maternal anxiety during pregnancy: effect on fetal behaviour at 38 to 40 weeks' gestation. J Dev Behav Paediatr 1995;16:391-6.

10 Henry C, Kabbaj M, Simon H, Le Moal M, Maccari S. Prenatal stress increases the hypothalamo-pituitary-adrenal axis response in young and adult rats. J Neuroendocrinol 1994;6:341-5.

11 Clarke AS, Soto A, Bergholz T, Schneider ML. Maternal gestational stress alters adaptive and social behaviour in adolescent rhesus monkey offspring. Inf Behav Develop 1996;19:451-6.

12 Gitau R, Cameron A, Fisk NM, Glover V. Fetal exposure to maternal cortisol. Lancet 1998;352:707-8.
13 Morishima HO, Pedersen H, Finster M. The influence of maternal psychological stress on the fetus. Am J Obstet Gynecol 1978;131:286-90.

14 Bower S, Schuchter K, Campbell S. Doppler ultrasound screening as part of routine antenatal scanning: prediction of pre-eclampsia and intrauterine growth retardation. Br J Obstet Gynaecol 1993;100:989-93.

15 Frusca T, Soregaroli M, Valcamonico A, Guandalini F, Danti L. Doppler velocimetry of the uterine arteries in nulliparous women. Early Hum Dev $1997 ; 48: 177-85$.

16 Harrington K, Cooper D, Lee C, Hecker K, Campbell S. Doppler ultrasound of the uterine arteries: the importance of bilateral notching in the prediction of pre-eclampsia, placental abruption or delivery of a small for gestational age baby. Ultrasound Obstet Gynecol 1996;7:182-8.

17 Spielberger CD, Gorusch RL, Lushene RE. STAI manual for the state-trait anxiety inventory. Palo Alto, CA: Consulting Psychologists Press, 1970.

18 Weinstein AM. Visual ERPs evidence for enhanced processing of threatening information in anxious university students. Biol Psychiat 1995;37:847-58.

19 Harrington K, Campbell SA. Colour atlas of Doppler ultrasonography in obstetrics. London: Arnold, 1995.

20 Field T, Morrow C, Healy B, Foster T, Adelstein D, Goldstein S. Mothers with zero Beck depression scores act more "depressed" with their infants. Dev Psychopathol 1992;3:253-62.

21 Spielberger CD. State-trait anxiety inventory for adults. Sampler set, manual, test, scoring key. Pao Alto, CA: Consulting Psychologists Press, 1983

22 Wolf F, Robertson WB, Brosens I. Inadequate maternal vascular response to placentation in pregnancies complicated by pre-eclampsia and smallfor-gestational age infants. BrJ Obstet Gynaecol 1986;93:1049-59.

23 Fried G, Thoresen M. Effects of neuropeptide $\mathrm{Y}$ and noradrenaline on uterine artery blood pressure and blood flow velocity in the pregnant guinea pig. Regul Pept 1990;28:1-9.

24 Hackett GA, Cohen-Overbeek T, Campbell S. The effect of exercise on uteroplacental Doppler waveforms in normal and complicated pregnancies. Obstet Gynecol 1992;79:919-23.

25 Bower SJ, Flack NJ, Sepulveda W, Talbert D, Fisk N. Uterine artery blood flow response to correction of amniotic fluid volume. Am J Obstet Gynecol 1995; 173:502-7.

26 Lees C, Langford E, Brown A, de Belder A, Pickles A, Martin JF, et al. The effects of s-nitroglutathione on platelet activation, hypertension, and uterine and fetal Doppler in severe preeclampsia. Obstet Gynecol $1996 ; 88: 14-9$.

27 Wadwa PD, Dunkel-Schetter C, Chicz-DeMet A, Porto M, Sandman CA Prenatal psychosocial factors and the neuroendocrine axis in human pregnancy. Psychosom Med 1996;58:432-46.

28 Starkman MN, Cameron OG, Nesse RM, Zelnik T. Periphera catecholamine levels and symptoms of anxiety: studies in patients with and without pheochromocytoma. Psychosom Med 1990;52:129-42.

29 Rosenfield CR, West J. Circulatory response to systemic infusion of norepinephrine in the pregnant ewe. Am J Obstet Gynecol 1976;127:376-83.

30 Haig D. Genetic conflicts in human pregnancy. Q Rev Biol 1993;68:495512

31 Barker DJP. Fetal origins of coronary heart disease. BMJ 1995;311:171-4

(Accepted 23 October 1998)

\section{Endpiece Alternative definitions}

Die: The singular of dice. We seldom hear the word, because there is a prohibitory proverb, "Never say die."

Ambrose Bierce, The Cynic's Word Book (1906), subsequently titled The Devil's Dictionary

\section{Notice of inadvertent duplicate publication}

The $B M J$ regrets that the paper "Diabetes mellitus and raised serum triglyceride concentration in treated hypertension-are they of prognostic importance? Observational study" by O Samuelsson et al (14 September 1996;313:660-3) was substantially similar to a paper published in the Journal of Internal Medicine entitled "The role of diabetes mellitus and hypertriglyceridaemia as coronary risk factors in treated hypertension: 15 years of follow up of antihypertensive treatment in middle aged men in the
Primary Prevention Trial in Göteborg, Sweden" (1994;235:217-27). The statistical evaluation is more thorough in the $B M J$ paper, but the articles present essentially the same data on the same patients. However, we were not told of the existence of the earlier paper, in contravention of our instructions to authors and of internationally agreed guidelines. Professor Samuelsson has apologised for not making us aware of the possible duplication. 